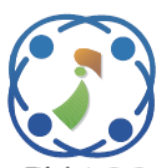

\title{
Integration of Evaluation Distance from Average Solution Approach with Information Entropy Weight for Diesel Engine Parameter Optimization
}

\author{
Shaaban M. Shaaban ${ }^{1,2 *}$ \\ A. M. Abd El-latif ${ }^{3,4}$ \\ ${ }^{I}$ Department of Engineering Basic science, Faculty of Engineering, \\ Menofiya University, Menofiya, 32511, Egypt \\ ${ }^{2}$ Department of Electrical Engineering, Faculty of Engineering, \\ Northern Border University, Arar,1321, Saudi Arabia \\ ${ }^{3}$ Mathematics Department, Faculty of Arts and Science, \\ Northern Border University, Rafha, Saudi Arabia \\ ${ }^{4}$ Mathematics Department, Faculty of Education, \\ Ain Shams University, Roxy, 11341, Cairo, Egypt. \\ * Corresponding author's Email: shabaan27@gmail.com
}

\begin{abstract}
This research depicts the utilization of a hybrid Multi Criteria Decision Making (MCDM) method for the determination of the best collection of operative parameters of a diesel engine. Nonetheless, selecting the best collection of operative parameters depends on both performance and emission properties that consist of various qualitative and quantitative parameters. The hybrid approach employs information entropy weight (IEW) and The Evaluation Based on Distance from Average Solution (EDAS) is proposed to rank available operating points for choosing the optimal combination of operating parameters of a diesel engine. Firstly, the strength of IWE is used to compute the relative weights of parameters. Then, EDAS technique is used to evaluate the alternatives ranking. The optimal values of performance and emission parameters: BP, SFC, Mech. Eff., BTE, CO, HC, CO2 and NOX emissions are $2.39 \mathrm{~kW}, 0.23(\mathrm{~kg} / \mathrm{kwh}), 52.51 \%, 36.72 \%, 0.04 \%, 43 \mathrm{ppm}, 2.8 \%$ and $304 \mathrm{ppm}$, respectively, at load, torque and fuel blend of $11 \mathrm{~kg}, 15.22 \mathrm{Nm}$ and B30, respectively. The results obtained by using the proposed integrated approach are validated by five various MCDM techniques. Namely, TOPSIS (Technique for Order Preference by Similarity Ideal Solution), WASPAS (Weighted Aggregated Sum Product Assessment), MOORA (Taguchi-based Multi-Objective Optimization by Ratio Analysis), WPAS (Weighted Product Assessment) and VIKOR (VIšekriterijumsko KOmpromisno Rangiranje) methods. The results indicate that the proposed integrated approach is capable of accurately ranking the operating points for diesel engine and the results well consistent with the other techniques. The proposed approach is clear in ideas and easy in computation, and calculation results are realistic as well.
\end{abstract}

Keywords: Multi criteria decision making, Information entropy weight, Evaluation based on distance from average solution, Technique for order preference by similarity ideal solution, Taguchi-based multi-objective optimization by ratio analysis.

\section{Introduction}

With passing the time, the reserves of fossil fuels are declining quicker, and petroleum products around the world are continuously increasing in prices. The high price of petroleum products has motivated the world towards searching for the alternative cheaper energy sources and reducing dependence on oil. Waste plastic oil (WPO) diesel blend is one of alternative source of fuels. Experimental studies show that numerous parameters influence diesel engine performance and emission properties [1]. However, the effect of the operating parameters is quite important, and the researchers have extensively studied their effect on engine performance. The optimal combinations of 
operating parameters enable the engine to perform best. Load, torque, fuel blend etc. are numerous parameters that influence engine performance. Best operating point selection is a type of decision making process requiring weighting of several parameters and evaluation and classification of alternatives. This view suggests that the problems with selecting operating points are a multidimensional nature and that methods for multicriteria decision making (MCDM) can be deal with them. From this viewpoint, the choice of operating point is multidimensional in nature and multicriteria -decision making (MCDM) approaches can be implemented. In the literature, various studies have been documented to solve the problem of optimum selection of diesel engine parameters. Reference [2] has applied response surface technique to optimize the operating engine variables like the compression ratio, load, and the biodiesel methanol palm oil blends and load to improve the thermal brake efficiency, the consumption of brakespecific fuel and emission parameters. Gray relational analysis was used to optimize the input parameters of the diesel engine, to enhance emissions and performance characteristics [3]. In [4] the genetic algorithm was used to optimize the CI engine operating parameters. Taguchi has been introduced in order to optimize the input parameters of diesel engines, rendering Jatropha biodiesel compatible [5]. Using a kernel based extreme learning and a biodiesel fuel cuckoo search [6] has optimized performance and exhaust emission of diesel engine. In many applications, such as supplier choosing, project selection, risk evaluation, etc., the multi-criteria decision-making strategy is very useful. An efficient and simple multi-criteria model was investigated for the selection of the grinding circuit using Taguchi-based Multi-Objective Optimization by Ratio Analysis (MOORA) [7]. For the assessment of green supply chain management, the VIKOR methodology (Vlsekriterijumska Optimizaciya I Kompromisno Resenje) was used [8]. Weighted aggregated sum product assessment (WASPAS) approach is applied for the solution of eight decision-making manufacturing issues [9]. TOPSIS (Technique for Order Preference by Similarity Ideal Solution) was applied for default models assessment of bank loan [10]. Simple Additive Weighting (SAW) was utilized for Personnel problem Selection [11]. The literature review reveals that little work has been done to optimize diesel engine input parameters for waste plastic oil fuel blend so that blends of waste plastic oil can be optimized in terms of different performance and emission parameters. In the recent study, three combinations of waste plastic oil fuel blend are considered for different torques under different conditions of diesel load. These parameters are optimized with respect to different performance and emission parameters using Evaluation Distance from Average Solution approach (EDAS). Information entropy (IEW) method was applied to compute the relative weights of the response variables. This paper organized as follows. EDAS method with its computation steps an MCDM tool and IEW with its computation steps and the methodology of the proposed integrated IEW and EDAS approach are presented in Section 2. The methodology of the proposed integrated IEW and EDAS approach is included in section3. The application of the integrated approach is demonstrated with the optimal operating point selection for diesel engine in section 4. A comparative analysis between the integrated EDAS and IEW method and some relevant methods for the problem solution is given in Section 5. Finally, in section 6 the conclusions are given.

\section{Methods}

\subsection{Evaluation based on distance from average solution (EDAS) method}

EDAS methodology was introduced by Keshavarz Ghorabaee [12]. EDAS, one of the MCDM methods, relies on an average solution to estimate the alternatives by taking into account two steps, which are PDA (average positive distance) and NDA (average negative distance). This approach defines instead of the distance from the ideal and negative optimal solutions as in the compromise MCDM methodologies like the VIKOR, TOPSIS, etc., the best alternative using the distance from the average solution (AV). The two key variables needed for the optimal choices are in that method: PDA and NDA, because the higher PDA and/or lower NDA values mean that the option is a better solution than the average. In the case of higher PDA values and lower NDA values, it is possible to analyze all solutions to a decisionmaking problem based on multiple sometimes mutually contradictory variables.

Assuming that there is a set of alternatives $m$ and $n$ criteria, the evaluation steps of EDAS method are given below [12]:

Step1. The parameters and alternatives are selected $\mathrm{i}$ $\mathrm{n}$ the first step of the decision problem.

Step 2. Decision Matrix (DM) X is built as shown. 


$$
X=\left[X_{i j}\right]_{m n}\left[\begin{array}{llll}
x_{11} x_{12} & \ldots & x_{1 n} \\
x_{21} x_{22} & \ldots & x_{2 n} \\
\vdots & \vdots & \ddots & \vdots \\
x_{m 1} x_{m 2} & \ldots & x_{m n}
\end{array}\right]
$$

Step 3: Taking into account all parameters the average solution (AV) is calculated as follows:

$$
A V=\left[A V_{j}\right]_{1 \times n} \text { Where, } A V_{j}=\frac{\sum_{i=1}^{m} x_{i j}}{m}
$$

Step 4: The estimation, based on the type of parameters (benefit and cost), of the positive distance to average (PDA) and negative distance to the NDA matrix is as follows:

$$
\begin{aligned}
& \mathrm{PDA}=\left[\mathrm{PDA}_{\mathrm{ij}}\right]_{\mathrm{m} \times \mathrm{n}} \\
& \mathrm{NDA}=\left[\mathrm{NDA}_{\mathrm{ij}}\right]_{\mathrm{m} \times \mathrm{n}}
\end{aligned}
$$

If the selected parameter is benefit then

$$
\begin{aligned}
& \mathrm{PDA}_{i j}=\frac{\max \left(0,\left(x_{i j}-A V_{j}\right)\right)}{A V_{j}} \\
& \mathrm{NDA}_{i j}=\frac{\max \left(0,\left(A V_{j}-x_{i j}\right)\right)}{A V_{j}}
\end{aligned}
$$

If the selected parameter is cost then

$$
\begin{aligned}
& P D A_{i j}=\frac{\max \left(0,\left(A V_{j}-x_{i j}\right)\right)}{A V_{j}} \\
& N D A_{i j}=\frac{\max \left(0,\left(x_{i j}-A V_{j}\right)\right)}{A V_{j}}
\end{aligned}
$$

Step 5: For all alternatives, the weighted sum of PDA $\left(\mathrm{SP}_{\mathrm{i}}\right)$ and the weighted sum of NDA $\left(\mathrm{SN}_{\mathrm{i}}\right)$ are computed as follows:

$$
\begin{aligned}
& S P_{i}=\sum_{j=1}^{m} w_{j} P D A_{i j} \\
& N P_{i}=\sum_{j=1}^{m} w_{j} N D A_{i j}
\end{aligned}
$$

Where, $w_{j}$ is the weight of the jth parameter.

Step 6: Standardize the SP and SN values for all alternatives as shown:

$$
\begin{aligned}
N S P_{i} & =\frac{S P_{i}}{\max _{i}\left(S P_{i}\right)} \\
N S N_{i} & =1-\frac{S N_{i}}{\max _{i}\left(S N_{i}\right)}
\end{aligned}
$$

Step7: Evaluate the appraisal score (AS) for all alternatives, as illustrated below:

$$
A S_{i}=\frac{1}{2}\left(N S P_{i}+N S N_{i}\right), 0 \leq A S_{i} \leq 1
$$

Step8: Alternatives are classified in descending order according to the $\mathrm{AS}_{\mathrm{i}}$ obtained. The alternative with the highest AS is the best of the alternatives.

\subsection{Information entropy weight method}

Entropy measures the system's disturbance degree, and the efficient data supplied can also be measured. Entropy can therefore be used for weight determination. While there is an enormous difference between the measured items on a particular index, entropy is smaller, indicating that the weight of indicators will increase when the indicators are given more useful information; on the contrary, the smaller the difference, the bigger the entropy, suggesting that the less information that is received by indicators, the smaller the difference. The entropy coefficient model is therefore an objective method of empowerment. The key steps for calculating the weights were accompanied by the use of entropy coefficient method [13]:

Step1. Normalization of the original assessment matrix

If there are $n$ assessment indicators and $\mathrm{m}$ assessment items, then original indicators value matrix $\mathrm{X}$ is created:

$$
X=\left[\begin{array}{lccc}
x_{11} & x_{12} & \ldots & x_{1 n} \\
x_{21} x_{22} & \ldots & x_{2 n} \\
\vdots & \vdots & \ddots & \vdots \\
x_{m 1} x_{m 2} & \ldots & x_{m n}
\end{array}\right]
$$

Every index may be attributed to two types of feature index: efficiency type, cost type. As regards efficiency type, the normalization construction function is:

$$
y_{i j}=\frac{x_{i j}-\min \left(x_{j}\right)}{\max \left(x_{j}\right)-\min \left(x_{j}\right)}
$$

While the construction function for the cost type is:

$$
y_{i j}=\frac{\max \left(x_{j}\right)-x_{i j}}{\max \left(x_{j}\right)-\min \left(x_{j}\right)}
$$

The standard Y matrix can be obtained after transformation and displayed below:

$$
Y=\left[\begin{array}{llll}
y_{11} y_{12} & \ldots & y_{1 n} \\
y_{21} y_{22} & \ldots & y_{2 n} \\
\vdots & \vdots & \ddots & \vdots \\
y_{m 1} y_{m 2} & \ldots & y_{m n}
\end{array}\right]
$$

Step 2. Definition of the entropy 
The definition of entropy of the $\mathrm{j}^{\text {th }}$ indicator is as follows during the evaluation of $n$ evaluation indicators and $\mathrm{m}$ assessment objects:

$$
\begin{aligned}
& e_{j}=-\frac{1}{\ln (m)} \sum_{i=1}^{m} p_{i j} \ln \left(p_{i j}\right), j=1,2, \ldots m \\
& \text { Where, } p_{i j}=y_{i j} / \sum_{i=1}^{m} y_{i j}
\end{aligned}
$$

Step3. Definition of the entropy weight

With the following formula, entropy weight can be calculated:

$$
w_{j}=\frac{\left(1-e_{j}\right)}{\left(n-\sum_{j=1}^{n} e_{j}\right)}, j=1,2, . .
$$

$w_{j}$ is defined in the formula as the entropy weight of the parameter $\mathrm{j}$.

\section{Proposed methodology}

The proposed methodology consists of three basic phases:

Phase I. Identification of criteria to apply in the model

Phase II. Entropy weight computation of information

Phase III. Ranking of alternatives by means of Distance from Average Solution approach.

\section{A) Criterion for selecting optimal operating parameters}

In the first stage, alternative diesel engine input parameters combination and their evaluation criteria are defined.

B) Computation of criteria weights using information entropy weight

The information entropy weight is used to evaluate the relative weights of performance and emission criteria in the second stage of the proposed methodology.

\section{C) Distance from Average Solution approach Computations}

The technique of the Distance from Average Solution specifies the rating of alternatives in which the best decision is taken to be nearest to the ideal and farthest from the unideal in the third stage.

The general framework of the suggested approach is shown in Fig. 1.

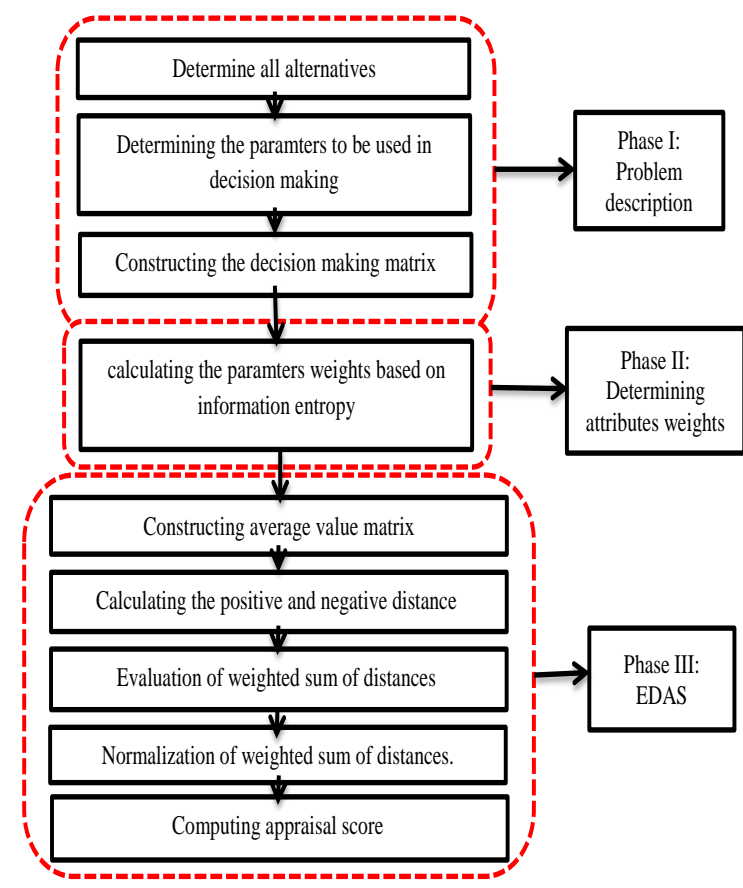

Figure. 1 The schematic structure of the proposed integrated IEW and EDAS approach

\section{Diesel engine parameter selection using the integrated IEW and EDAS approach}

In this section, optimal operating point combination choosing problem of a diesel engine is studied with the proposed approach. By this way, the implementation of the integrated approach is shown. 44 operating points are evaluated in terms of ten criteria in this application. The performance parameters selected in the current study are Brake power (BP), Specific fuel consumption (SFC), Mechanical efficiency (Mech. Eff.) and Brake thermal efficiency (BTE) and the chosen parameters for emission are the levels of carbon monoxide (CO), Hydro carbon (HC), carbon dioxide (CO2) and oxides of nitrogen (NOx(emissions were measured are considered as criteria of diesel engine parameter selection. After establishing the alternatives and parameters, integrated method based on information entropy weight and EDAS approach is applied for assessment the diesel engine operating points. IEW is proposed to compute the weights of the parameters. Then, the ordering of the alternatives is obtained using EDAS technique. Lastly, the optimal operating point is chosen that has the maximum AS.

The weights of the parameters are calculated with IEW method, these parameters weights obtained with the IEW approach are shown in Table 1. 
Table 1. Parameters weight

\begin{tabular}{|c|c|c|c|c|c|c|c|c|}
\hline Parameter & $\begin{array}{c}\mathrm{BP} \\
(\mathrm{kw}) \\
(\mathrm{Max})\end{array}$ & $\begin{array}{c}\mathrm{SFC} \\
(\mathrm{kg} / \mathrm{kwh}) \\
(\mathrm{Min})\end{array}$ & $\begin{array}{c}\text { Mech. } \\
\text { Eff.(\%) } \\
(\mathrm{Max})\end{array}$ & $\begin{array}{c}\mathrm{BTE} \\
(\%) \\
(\mathrm{Max})\end{array}$ & $\begin{array}{c}\mathrm{CO} \\
(\%) \\
(\mathrm{Min})\end{array}$ & $\begin{array}{c}\mathrm{HC} \\
(\mathrm{ppm}) \\
(\mathrm{Min})\end{array}$ & $\begin{array}{c}\mathrm{CO} 2 \\
(\%) \\
(\mathrm{Min})\end{array}$ & $\begin{array}{c}\text { NOX (ppm) } \\
(\mathrm{Min})\end{array}$ \\
\hline Weights & 0.2379 & 0.2733 & 0.1276 & 0.1280 & 0.0135 & 0.0271 & 0.0469 & 0.1409 \\
\hline
\end{tabular}

Once the weights of the parameters are calculated with IEW technique, the ordering of the optimal operating point combination is evaluated with EDAS approach. In EDAS approach, first of all (DM) is developed as given in Table 2. In optimal operating point selection problem, (BP), (Mech. Eff.) and (BTE) criteria have to be maximized, and the (SFC), (CO), (HC), (CO2) and (NOx ( have to be minimized. So (SFC), (CO), (HC), (CO2), and (NOx( are cost criteria whereas (BP), (Mech. Eff.) and (BTE) are benefit criteria.

As (DM) is established, AV based on all parameters are calculated. These AV values can be seen at the last row of Table 2. The PDA matrix is subsequently developed to the benefit and cost parameters. Table 3 lists this matrix.

Then, the NDA matrix is established as provided in Table 4 by utilizing the benefit parameters and the cost parameters.

Afterward, for all alternatives, weighted sums PDA and NDA are determined. Here, the weights are obtained through IWE approach.Then, $\mathrm{SP}_{\mathrm{i}}$ and $\mathrm{SN}_{\mathrm{i}}$ values are calculated as shown in the first tow column of Table 5. SP and SN values are standardized for all alternatives in order to determine $\mathrm{NSP}_{\mathrm{i}}$ and $\mathrm{NSN}_{\mathrm{i}}$ values in columns 3 and 4 of Table 5.Lastly, in the last two columns of Table 5, the ranking and AS for all operational points are determined.

\section{A comparative analysis}

The aim of this study is to apply the effective and relatively integrated IEW and EDAS approach to the optimal operating point selection problem as a reasonable and effective MCDM method. In order to evaluate whether the proposed approach is feasible and efficient, the ranking results of the proposed approach is compared with the different MCDM methods (such as MOORA, TOPSIS, VIKOR, WSPAS, and WASPAS). Comparative evaluations with previous works [7-11] are made to demonstrate the performance of the integrated EDAS and IEW methodology as MCDM technique to for optimal operating point determination of diesel engine. In this study, the suggested approach is compared with TOPSIS [10], WASPAS [9], MOORA [7], WPAS [11] and VIKOR [8] approaches. Table 6 shows the results for optimal selection of operating points using different MCDM methods.

We use the Spearman's rank-correlation test a technique for determining whether there is significant rank-correlation between two sets of values. The results of comparison between all considered methods are given in Table 7.

The results show that the IEW and EDAS integrated approach could find similar solutions as compared to other MCDM methods according to Spearman's rank correlational values in Table 7.

\section{Conclusions}

In this paper, an integrated approach was suggested to find the optimal combination of operating parameters of a diesel engine. This approach is based on IEW and EDAS. In IEW method, weights of the parameters are determined, while EDAS method is applied in ranking of operating points. Based on the engine performance parameters like (BP), (SFC), (Mech. Eff.), and (BTE) and the engine emission parameters like (CO), (HC), (CO2). And (NOx) the optimum engine parameters at load of $11 \mathrm{~kg}$, fuel blend B30, and 15.22 Nm torque, where the values of the BP, SFC, Mech. Eff., BTE , CO, HC , CO2, and NOX were found to be $2.39 \mathrm{~kW}, 0.23(\mathrm{~kg} / \mathrm{kwh}), 52.51 \%$, $36.72 \%, 0.04 \%, 43 \mathrm{ppm}, 2.8 \%$ and $304 \mathrm{ppm}$, respectively. The results of the integrated IEW and EDAS approach were compared with other MCDM techniques like MOORA, TOPSIS, VIKOR, WSPAS, and WASPAS. The results show that the methodology introduced is compatible with the other MCDM methods. The Spearman correlation coefficient between the proposed approach and the different MCDM methods different methods lie between 0.903-1.0 which show that the ranks are in perfect agreement and have strong correlations with each other. The results indicate that the proposed integrated approach is capable of accurately ranking 
Table 2. Diesel engine decision matrix

\begin{tabular}{|c|c|c|c|c|c|c|c|c|c|c|c|}
\hline \multirow[t]{2}{*}{$\begin{array}{l}\text { Exp. } \\
\text { No. }\end{array}$} & \multicolumn{3}{|c|}{ Operating parameter } & \multicolumn{5}{|c|}{$\begin{array}{c}\text { Engine performance } \\
\text { values }\end{array}$} & \multicolumn{3}{|c|}{$\begin{array}{c}\text { Emission } \\
\text { characteristics } \\
\text { Values }\end{array}$} \\
\hline & $\begin{array}{l}\text { Load } \\
(\mathrm{Kg})\end{array}$ & $\begin{array}{l}\text { Torque } \\
(\mathrm{Nm})\end{array}$ & Fuel & $\begin{array}{l}\mathrm{BP} \\
(\mathrm{kw}) \\
(\mathrm{Max})\end{array}$ & $\begin{array}{c}\text { SFC } \\
(\mathrm{kg} / \mathrm{kwh}) \\
(\mathrm{Min})\end{array}$ & $\begin{array}{l}\text { Mech. } \\
\text { Eff.(\%) } \\
\text { (Max) }\end{array}$ & $\begin{array}{c}\mathrm{BTE} \\
(\%) \\
(\mathrm{Max})\end{array}$ & $\begin{array}{c}\mathrm{CO} \\
(\%) \\
(\mathrm{Min})\end{array}$ & $\begin{array}{c}\mathrm{HC} \\
(\mathrm{ppm}) \\
(\mathrm{Min})\end{array}$ & $\begin{array}{c}\mathrm{CO} 2 \\
(\%) \\
(\mathrm{Min})\end{array}$ & $\begin{array}{l}\text { NOX } \\
(\mathrm{ppm}) \\
(\mathrm{Min})\end{array}$ \\
\hline 1 & 1 & 1.38 & Diesel & 0.22 & 1.44 & 10.77 & 5.97 & 0.05 & 26 & 1.7 & 91 \\
\hline 2 & 1 & 1.38 & B10 & 0.22 & 1.3 & 9.41 & 6.58 & 0.04 & 39 & 1.6 & 92 \\
\hline 3 & 1 & 1.38 & B20 & 0.22 & 1.17 & 10.36 & 7.32 & 0.04 & 36 & 1.6 & 95 \\
\hline 4 & 1 & 1.38 & B30 & 0.22 & 1.31 & 9.14 & 6.53 & 0.04 & 37 & 1.5 & 93 \\
\hline 5 & 2 & 2.77 & Diesel & 0.43 & 0.75 & 19.44 & 11.47 & 0.05 & 30 & 1.7 & 107 \\
\hline 6 & 2 & 2.77 & B10 & 0.43 & 0.71 & 17.21 & 12 & 0.05 & 29 & 1.8 & 114 \\
\hline 7 & 2 & 2.77 & B20 & 0.43 & 0.71 & 18.77 & 12.16 & 0.05 & 35 & 1.7 & 109 \\
\hline 8 & 2 & 2.77 & B30 & 0.43 & 0.71 & 16.74 & 12.12 & 0.05 & 42 & 1.7 & 108 \\
\hline 9 & 3 & 4.15 & Diesel & 0.65 & 0.52 & 26.58 & 16.57 & 0.05 & 23 & 1.8 & 111 \\
\hline 10 & 3 & 4.15 & B10 & 0.65 & 0.51 & 23.76 & 16.66 & 0.06 & 41 & 1.9 & 118 \\
\hline 11 & 3 & 4.15 & B20 & 0.65 & 0.51 & 25.74 & 16.75 & 0.05 & 43 & 1.8 & 134 \\
\hline 12 & 3 & 4.15 & B30 & 0.65 & 0.52 & 23.17 & 16.35 & 0.05 & 42 & 1.8 & 124 \\
\hline 13 & 4 & 5.53 & Diesel & 0.87 & 0.42 & 32.55 & 20.57 & 0.05 & 32 & 2.1 & 140 \\
\hline 14 & 4 & 5.53 & B10 & 0.87 & 0.43 & 29.36 & 20.13 & 0.05 & 34 & 2.1 & 154 \\
\hline 15 & 4 & 5.53 & B20 & 0.87 & 0.41 & 31.6 & 20.94 & 0.05 & 38 & 2 & 144 \\
\hline 16 & 4 & 5.53 & B30 & 0.87 & 0.42 & 28.68 & 20.21 & 0.05 & 36 & 2 & 145 \\
\hline 17 & 5 & 6.92 & Diesel & 1.09 & 0.36 & 37.63 & 24.06 & 0.06 & 34 & 2.2 & 154 \\
\hline 18 & 5 & 6.92 & B10 & 1.09 & 0.38 & 34.19 & 22.72 & 0.05 & 42 & 2.3 & 193 \\
\hline 19 & 5 & 6.92 & B20 & 1.09 & 0.35 & 36.61 & 24.47 & 0.05 & 42 & 2 & 167 \\
\hline 20 & 5 & 6.92 & B30 & 1.09 & 0.37 & 33.45 & 23.24 & 0.05 & 48 & 2 & 169 \\
\hline 21 & 6 & 8.3 & Diesel & 1.3 & 0.32 & 41.99 & 26.96 & 0.06 & 35 & 2.4 & 181 \\
\hline 22 & 6 & 8.3 & B10 & 1.3 & 0.34 & 38.4 & 24.99 & 0.05 & 35 & 2.6 & 238 \\
\hline 23 & 6 & 8.3 & B20 & 1.3 & 0.33 & 40.94 & 26.29 & 0.05 & 35 & 2.5 & 220 \\
\hline 24 & 6 & 8.3 & B30 & 1.3 & 0.32 & 37.63 & 27.06 & 0.05 & 52 & 2.1 & 181 \\
\hline 25 & 7 & 9.68 & Diesel & 1.52 & 0.3 & 45.79 & 29 & 0.06 & 41 & 2.7 & 215 \\
\hline 26 & 7 & 9.68 & B10 & 1.52 & 0.3 & 42.11 & 28.37 & 0.05 & 32 & 2.4 & 250 \\
\hline 27 & 7 & 9.68 & B20 & 1.52 & 0.29 & 44.71 & 29.64 & 0.06 & 47 & 2.6 & 238 \\
\hline 28 & 7 & 9.68 & B30 & 1.52 & 0.29 & 41.31 & 29.47 & 0.04 & 50 & 2.3 & 214 \\
\hline 29 & 8 & 11.07 & Diesel & 1.74 & 0.28 & 49.11 & 30.6 & 0.04 & 26 & 3 & 309 \\
\hline 30 & 8 & 11.07 & B10 & 1.74 & 0.27 & 45.39 & 32.07 & 0.04 & 35 & 2.2 & 275 \\
\hline 31 & 8 & 11.07 & B20 & 1.74 & 0.27 & 48.03 & 31.74 & 0.06 & 45 & 2.8 & 276 \\
\hline 32 & 8 & 11.07 & B30 & 1.74 & 0.27 & 44.58 & 31.57 & 0.05 & 54 & 2.5 & 245 \\
\hline 33 & 9 & 12.45 & Diesel & 1.95 & 0.27 & 52.06 & 31.96 & 0.04 & 35 & 3.1 & 348 \\
\hline 34 & 9 & 12.45 & B10 & 1.95 & 0.25 & 48.32 & 33.74 & 0.04 & 41 & 2.7 & 297 \\
\hline 35 & 9 & 12.45 & B20 & 1.95 & 0.26 & 50.97 & 33.25 & 0.05 & 42 & 3.2 & 325 \\
\hline 36 & 9 & 12.45 & B30 & 1.95 & 0.25 & 47.5 & 33.93 & 0.04 & 39 & 2.5 & 249 \\
\hline 37 & 10 & 13.83 & Diesel & 2.17 & 0.25 & 54.68 & 33.9 & 0.06 & 42 & 3.4 & 351 \\
\hline 38 & 10 & 13.83 & B10 & 2.17 & 0.24 & 50.96 & 35.03 & 0.05 & 34 & 2.9 & 312 \\
\hline 39 & 10 & 13.83 & B20 & 2.17 & 0.24 & 53.6 & 36.41 & 0.05 & 53 & 3.1 & 334 \\
\hline 40 & 10 & 13.83 & B30 & 2.17 & 0.24 & 50.13 & 36.08 & 0.04 & 40 & 2.6 & 281 \\
\hline 41 & 11 & 15.22 & Diesel & 2.39 & 0.25 & 57.03 & 34.91 & 0.05 & 43 & 4.4 & 373 \\
\hline 42 & 11 & 15.22 & B10 & 2.39 & 0.23 & 53.34 & 36.49 & 0.04 & 39 & 3 & 346 \\
\hline 43 & 11 & 15.22 & B20 & 2.39 & 0.23 & 55.96 & 37.69 & 0.05 & 56 & 3.3 & 410 \\
\hline 44 & 11 & 15.22 & B30 & 2.39 & 0.23 & 52.51 & 36.72 & 0.04 & 43 & 2.8 & 304 \\
\hline AV & & & & 1.3027 & 0.4505 & 36.868 & 24.652 & 0.0489 & 39.159 & 2.373 & 212.3 \\
\hline
\end{tabular}

the operating points for diesel engine and the results well consistent with the other techniques. We can, therefore, conclude that the integrated EDAS and IEW approach is powerful in the optimization of International Journal of Intelligent Engineering and Systems, Vol.13, No.3, 2020 diesel engine parameters. In future studies, stander deviation method can be applied for weights of the criteria evaluation and $r$ the alternatives ranking can be established using various MCDM methods such 
as ELECTRE, PROMETHEE and AHP for diesel engine parameter optimization.

\section{References}

[1] S. Ananthakumar, S. Jayabal, and P. Thirumal, "Investigation on performance, emission and combustion characteristics of variable compression engine fuelled with diesel, waste plastics oil blends", Brazilian Society of Mechanical Sciences and Engineering, Vol. 39, pp. 19-28, 2017.

[2] Y. D. Bharadwaz, B. G. Rao, V. D. Rao, and C. Anusha, "Improvement of biodiesel methanol blends performance in a variable compression ratio engine using response surface methodology", Alexandria Engineering Journal, Vol. 55, pp. 1201-09, 2016.

[3] K. P. Rao and B. V. A. Rao, "Parametric optimization for performance and emission of an IDI engine with Mahua Biodiesel", Egyptian Journal of Petroleum, Vol. 26, No. 3, pp. 73343, 2017.

[4] S. V. Channapattana, A. A. Pawar, and P. G. Kamble, "Optimisation of operating parameters of DI-CI engine fuelled with second generation Bio-fuel and development of ANN based prediction model", Applied Energy, Vol. 187, pp. 84-95, 2017.

[5] T. Ganapathy, K. Murugesan, and R. P. Gakkhar, "Performance optimization of Jatropha biodiesel engine model using Taguchi approach", Applied Energy, Vol. 86, pp. 24762486, 2009.

[6] P. K. Wong, K. I. Wong, C. M. Vong, and C. S. Cheung, "Modelling and optimization of biodiesel engine performance using Kernel based extreme machine and cuckoo search", Renewable Energy, Vol. 74, pp. 640-47, 2015.

[7] D. Stanujkic, N. Magdalinovic, D. Milanovic, S. Magdalinovic, and G. Popovic, "An efficient and simple multiple criteria model for a grinding circuit selection based on MOORA method", Informatica, Vol. 25, No. 1, pp. 7393, 2014.

[8] R. Rostamzadeh, K. Govindan, A. Esmaeili, and M. Sabaghi, "Application of fuzzy VIKOR for evaluation of green supply chain management practices", Ecological Indicators, Vol. 49, pp. 188-203, 2015.

[9] S. Chakraborty and E. K. Zavadskas, "Applications of WASPAS method in manufacturing decision making", Informatica, Vol. 25, No. 1, pp. 1-20, 2014.

[10] G. Kou, Y. Peng, and C. Lu, "MCDM approach to evaluating bank loan default models", Technological and Economic Development of Economy, Vol. 20, No. 2, pp. 292-311, 2014.

[11] A. Afshari, M. Mojahed, and R. M. Yusuff, "Simple Additive Weighting approach to Personnel Selection problem. International Journal of Innovation", Management and Technology, Vol. 1, No. 5, pp. 511-515, 2010.

[12] M. K. Ghorabaee, E. K. Zavadskas, L. Olfat, and Z. Turskis, "Multi-criteria inventory classification using a new method of evaluation based on distance from average solution (EDAS)", Informatica, Vol. 26, No. 3, pp. 435451, 2015.

[13] J. Wu, H. Chi, and L. Chi, "A Cloud Modelbased Approach for Facial Expression Synthesis", Journal of Multimedia, Vol. 6, No. 2, pp. 217-224, 2011. 
Table 3. Positive distance from average matrix

\begin{tabular}{|c|c|c|c|c|c|c|c|c|}
\hline $\begin{array}{l}\text { Exp. } \\
\text { No. }\end{array}$ & $\begin{array}{c}\mathrm{BP} \\
(\mathrm{kw}) \\
(\mathrm{Max}) \\
\end{array}$ & $\begin{array}{c}\mathrm{SFC} \\
(\mathrm{kg} / \mathrm{kwh}) \\
(\mathrm{Min})\end{array}$ & $\begin{array}{c}\text { Mech. } \\
\text { Eff. }(\%) \\
(\text { Max })\end{array}$ & $\begin{array}{l}\text { BTE } \\
(\%) \\
(\operatorname{Max}) \\
\end{array}$ & $\begin{array}{l}\mathrm{CO} \\
(\%) \\
(\mathrm{Min}) \\
\end{array}$ & $\begin{array}{c}\mathrm{HC} \\
(\mathrm{ppm}) \\
(\mathrm{Min}) \\
\end{array}$ & $\begin{array}{c}\mathrm{CO} 2 \\
(\%) \\
(\mathrm{Min}) \\
\end{array}$ & $\begin{array}{c}\text { NOX (ppm) } \\
\text { (Min) }\end{array}$ \\
\hline 1 & 0 & 0 & 0 & 0 & 0 & 0.336 & 0.284 & 0.571 \\
\hline 2 & 0 & 0 & 0 & 0 & 0.181 & 0.004 & 0.326 & 0.566 \\
\hline 3 & 0 & 0 & 0 & 0 & 0.181 & 0.081 & 0.326 & 0.552 \\
\hline 4 & 0 & 0 & 0 & 0 & 0.181 & 0.055 & 0.368 & 0.562 \\
\hline 5 & 0 & 0 & 0 & 0 & 0 & 0.234 & 0.284 & 0.496 \\
\hline 6 & 0 & 0 & 0 & 0 & 0 & 0.259 & 0.241 & 0.463 \\
\hline 7 & 0 & 0 & 0 & 0 & 0 & 0.106 & 0.284 & 0.486 \\
\hline 8 & 0 & 0 & 0 & 0 & 0 & 0 & 0.284 & 0.491 \\
\hline 9 & 0 & 0 & 0 & 0 & 0 & 0.413 & 0.241 & 0.477 \\
\hline 10 & 0 & 0 & 0 & 0 & 0 & 0 & 0.199 & 0.444 \\
\hline 11 & 0 & 0 & 0 & 0 & 0 & 0 & 0.241 & 0.368 \\
\hline 12 & 0 & 0 & 0 & 0 & 0 & 0 & 0.241 & 0.415 \\
\hline 13 & 0 & 0.068 & 0 & 0 & 0 & 0.183 & 0.115 & 0.34 \\
\hline 14 & 0 & 0.045 & 0 & 0 & 0 & 0.132 & 0.115 & 0.274 \\
\hline 15 & 0 & 0.09 & 0 & 0 & 0 & 0.03 & 0.157 & 0.321 \\
\hline 16 & 0 & 0.068 & 0 & 0 & 0 & 0.081 & 0.157 & 0.316 \\
\hline 17 & 0 & 0.201 & 0.021 & 0 & 0 & 0.132 & 0.073 & 0.274 \\
\hline 18 & 0 & 0.156 & 0 & 0 & 0 & 0 & 0.031 & 0.09 \\
\hline 19 & 0 & 0.223 & 0 & 0 & 0 & 0 & 0.157 & 0.213 \\
\hline 20 & 0 & 0.179 & 0 & 0 & 0 & 0 & 0.157 & 0.203 \\
\hline 21 & 0 & 0.29 & 0.139 & 0.094 & 0 & 0.106 & 0 & 0.147 \\
\hline 22 & 0 & 0.245 & 0.042 & 0.014 & 0 & 0.106 & 0 & 0 \\
\hline 23 & 0 & 0.267 & 0.11 & 0.066 & 0 & 0.106 & 0 & 0 \\
\hline 24 & 0 & 0.29 & 0.021 & 0.098 & 0 & 0 & 0.115 & 0.147 \\
\hline 25 & 0.167 & 0.334 & 0.242 & 0.176 & 0 & 0 & 0 & 0 \\
\hline 26 & 0.167 & 0.334 & 0.142 & 0.151 & 0 & 0.183 & 0 & 0 \\
\hline 27 & 0.167 & 0.356 & 0.213 & 0.202 & 0 & 0 & 0 & 0 \\
\hline 28 & 0.167 & 0.356 & 0.12 & 0.195 & 0.181 & 0 & 0.031 & 0 \\
\hline 29 & 0.336 & 0.378 & 0.332 & 0.241 & 0.181 & 0.336 & 0 & 0 \\
\hline 30 & 0.336 & 0.401 & 0.231 & 0.301 & 0.181 & 0.106 & 0.073 & 0 \\
\hline 31 & 0.336 & 0.401 & 0.303 & 0.288 & 0 & 0 & 0 & 0 \\
\hline 32 & 0.336 & 0.401 & 0.209 & 0.281 & 0 & 0 & 0 & 0 \\
\hline 33 & 0.497 & 0.401 & 0.412 & 0.296 & 0.181 & 0.106 & 0 & 0 \\
\hline 34 & 0.497 & 0.445 & 0.311 & 0.369 & 0.181 & 0 & 0 & 0 \\
\hline 35 & 0.497 & 0.423 & 0.382 & 0.349 & 0 & 0 & 0 & 0 \\
\hline 36 & 0.497 & 0.445 & 0.288 & 0.376 & 0.181 & 0.004 & 0 & 0 \\
\hline 37 & 0.666 & 0.445 & 0.483 & 0.375 & 0 & 0 & 0 & 0 \\
\hline 38 & 0.666 & 0.467 & 0.382 & 0.421 & 0 & 0.132 & 0 & 0 \\
\hline 39 & 0.666 & 0.467 & 0.454 & 0.477 & 0 & 0 & 0 & 0 \\
\hline 40 & 0.666 & 0.467 & 0.36 & 0.464 & 0.181 & 0 & 0 & 0 \\
\hline 41 & 0.835 & 0.445 & 0.547 & 0.416 & 0 & 0 & 0 & 0 \\
\hline 42 & 0.835 & 0.489 & 0.447 & 0.48 & 0.181 & 0.004 & 0 & 0 \\
\hline 43 & 0.835 & 0.489 & 0.518 & 0.529 & 0 & 0 & 0 & 0 \\
\hline 44 & 0.835 & 0.489 & 0.424 & 0.49 & 0.181 & 0 & 0 & 0 \\
\hline
\end{tabular}


Table 4. Negative distance from average matrix

\begin{tabular}{|c|c|c|c|c|c|c|c|c|}
\hline $\begin{array}{l}\text { Exp. } \\
\text { No. }\end{array}$ & $\begin{array}{l}\text { BP } \\
\text { (kw) } \\
\text { (Max) }\end{array}$ & $\begin{array}{c}\mathrm{SFC} \\
(\mathrm{kg} / \mathrm{kwh}) \\
(\mathrm{Min})\end{array}$ & $\begin{array}{l}\text { Mech. } \\
\text { Eff.(\%) } \\
(\text { Max })\end{array}$ & $\begin{array}{l}\text { BTE } \\
(\%) \\
(\mathrm{Max})\end{array}$ & $\begin{array}{l}\mathrm{CO} \\
(\%) \\
(\mathrm{Min})\end{array}$ & $\begin{array}{l}\mathrm{HC} \\
(\mathrm{ppm}) \\
\text { (Min) }\end{array}$ & $\begin{array}{l}\mathrm{CO} 2 \\
(\%) \\
(\mathrm{Min})\end{array}$ & $\begin{array}{l}\text { NOX (ppm) } \\
\quad(\text { Min) }\end{array}$ \\
\hline 1 & 0.831 & 2.197 & 0.708 & 0.758 & 0.023 & 0 & 0 & 0 \\
\hline 2 & 0.831 & 1.886 & 0.745 & 0.733 & 0 & 0 & 0 & 0 \\
\hline 3 & 0.831 & 1.597 & 0.719 & 0.703 & 0 & 0 & 0 & 0 \\
\hline 4 & 0.831 & 1.908 & 0.752 & 0.735 & 0 & 0 & 0 & 0 \\
\hline 5 & 0.67 & 0.665 & 0.473 & 0.535 & 0.023 & 0 & 0 & 0 \\
\hline 6 & 0.67 & 0.576 & 0.533 & 0.513 & 0.023 & 0 & 0 & 0 \\
\hline 7 & 0.67 & 0.576 & 0.491 & 0.507 & 0.023 & 0 & 0 & 0 \\
\hline 8 & 0.67 & 0.576 & 0.546 & 0.508 & 0.023 & 0.073 & 0 & 0 \\
\hline 9 & 0.501 & 0.154 & 0.279 & 0.328 & 0.023 & 0 & 0 & 0 \\
\hline 10 & 0.501 & 0.132 & 0.356 & 0.324 & 0.228 & 0.047 & 0 & 0 \\
\hline 11 & 0.501 & 0.132 & 0.302 & 0.321 & 0.023 & 0.098 & 0 & 0 \\
\hline 12 & 0.501 & 0.154 & 0.372 & 0.337 & 0.023 & 0.073 & 0 & 0 \\
\hline 13 & 0.332 & 0 & 0.117 & 0.166 & 0.023 & 0 & 0 & 0 \\
\hline 14 & 0.332 & 0 & 0.204 & 0.183 & 0.023 & 0 & 0 & 0 \\
\hline 15 & 0.332 & 0 & 0.143 & 0.151 & 0.023 & 0 & 0 & 0 \\
\hline 16 & 0.332 & 0 & 0.222 & 0.18 & 0.023 & 0 & 0 & 0 \\
\hline 17 & 0.163 & 0 & 0 & 0.024 & 0.228 & 0 & 0 & 0 \\
\hline 18 & 0.163 & 0 & 0.073 & 0.078 & 0.023 & 0.073 & 0 & 0 \\
\hline 19 & 0.163 & 0 & 0.007 & 0.007 & 0.023 & 0.073 & 0 & 0 \\
\hline 20 & 0.163 & 0 & 0.093 & 0.057 & 0.023 & 0.226 & 0 & 0 \\
\hline 21 & 0.002 & 0 & 0 & 0 & 0.228 & 0 & 0.011 & 0 \\
\hline 22 & 0.002 & 0 & 0 & 0 & 0.023 & 0 & 0.096 & 0.122 \\
\hline 23 & 0.002 & 0 & 0 & 0 & 0.023 & 0 & 0.054 & 0.037 \\
\hline 24 & 0.002 & 0 & 0 & 0 & 0.023 & 0.328 & 0 & 0 \\
\hline 25 & 0 & 0 & 0 & 0 & 0.228 & 0.047 & 0.138 & 0.013 \\
\hline 26 & 0 & 0 & 0 & 0 & 0.023 & 0 & 0.011 & 0.178 \\
\hline 27 & 0 & 0 & 0 & 0 & 0.228 & 0.2 & 0.096 & 0.122 \\
\hline 28 & 0 & 0 & 0 & 0 & 0 & 0.277 & 0 & 0.009 \\
\hline 29 & 0 & 0 & 0 & 0 & 0 & 0 & 0.264 & 0.457 \\
\hline 30 & 0 & 0 & 0 & 0 & 0 & 0 & 0 & 0.296 \\
\hline 31 & 0 & 0 & 0 & 0 & 0.228 & 0.149 & 0.18 & 0.301 \\
\hline 32 & 0 & 0 & 0 & 0 & 0.023 & 0.379 & 0.054 & 0.155 \\
\hline 33 & 0 & 0 & 0 & 0 & 0 & 0 & 0.307 & 0.64 \\
\hline 34 & 0 & 0 & 0 & 0 & 0 & 0.047 & 0.138 & 0.4 \\
\hline 35 & 0 & 0 & 0 & 0 & 0.023 & 0.073 & 0.349 & 0.532 \\
\hline 36 & 0 & 0 & 0 & 0 & 0 & 0 & 0.054 & 0.174 \\
\hline 37 & 0 & 0 & 0 & 0 & 0.228 & 0.073 & 0.433 & 0.655 \\
\hline 38 & 0 & 0 & 0 & 0 & 0.023 & 0 & 0.222 & 0.471 \\
\hline 39 & 0 & 0 & 0 & 0 & 0.023 & 0.353 & 0.307 & 0.574 \\
\hline 40 & 0 & 0 & 0 & 0 & 0 & 0.021 & 0.096 & 0.325 \\
\hline 41 & 0 & 0 & 0 & 0 & 0.023 & 0.098 & 0.854 & 0.758 \\
\hline 42 & 0 & 0 & 0 & 0 & 0 & 0 & 0.264 & 0.631 \\
\hline 43 & 0 & 0 & 0 & 0 & 0.023 & 0.43 & 0.391 & 0.933 \\
\hline 44 & 0 & 0 & 0 & 0 & 0 & 0.098 & 0.18 & 0.433 \\
\hline
\end{tabular}


Table 5. Integrated method results

\begin{tabular}{|c|c|c|c|c|c|c|}
\hline $\begin{array}{c}\text { Exp. } \\
\text { No. }\end{array}$ & $\mathrm{SP}_{\mathrm{i}}$ & $\mathrm{SN}_{\mathrm{i}}$ & $\mathrm{NSP}_{\mathrm{i}}$ & $\mathrm{NSN}_{\mathrm{i}}$ & $\mathrm{ASi}$ & Rank \\
\hline 1 & 0.168 & 0.671 & 0.475 & 0.000 & 0.238 & 44 \\
\hline 2 & 0.158 & 0.600 & 0.448 & 0.105 & 0.276 & 43 \\
\hline 3 & 0.168 & 0.554 & 0.477 & 0.175 & 0.326 & 41 \\
\hline 4 & 0.174 & 0.607 & 0.493 & 0.095 & 0.294 & 42 \\
\hline 5 & 0.143 & 0.358 & 0.405 & 0.466 & 0.435 & 38 \\
\hline 6 & 0.142 & 0.334 & 0.401 & 0.502 & 0.452 & 37 \\
\hline 7 & 0.123 & 0.333 & 0.350 & 0.504 & 0.427 & 39 \\
\hline 8 & 0.121 & 0.346 & 0.342 & 0.484 & 0.413 & 40 \\
\hline 9 & 0.159 & 0.198 & 0.452 & 0.705 & 0.578 & 26 \\
\hline 10 & 0.097 & 0.230 & 0.276 & 0.658 & 0.467 & 36 \\
\hline 11 & 0.086 & 0.205 & 0.244 & 0.694 & 0.469 & 35 \\
\hline 12 & 0.100 & 0.213 & 0.284 & 0.683 & 0.483 & 34 \\
\hline 13 & 0.099 & 0.101 & 0.282 & 0.849 & 0.565 & 27 \\
\hline 14 & 0.083 & 0.108 & 0.236 & 0.840 & 0.538 & 32 \\
\hline 15 & 0.084 & 0.098 & 0.239 & 0.854 & 0.546 & 31 \\
\hline 16 & 0.095 & 0.112 & 0.269 & 0.833 & 0.551 & 30 \\
\hline 17 & 0.099 & 0.066 & 0.280 & 0.902 & 0.591 & 24 \\
\hline 18 & 0.039 & 0.059 & 0.112 & 0.912 & 0.512 & 33 \\
\hline 19 & 0.084 & 0.043 & 0.237 & 0.935 & 0.586 & 25 \\
\hline 20 & 0.081 & 0.083 & 0.230 & 0.876 & 0.553 & 29 \\
\hline 21 & 0.111 & 0.040 & 0.314 & 0.941 & 0.627 & 20 \\
\hline 22 & 0.060 & 0.038 & 0.171 & 0.943 & 0.557 & 28 \\
\hline 23 & 0.079 & 0.022 & 0.223 & 0.967 & 0.595 & 23 \\
\hline 24 & 0.105 & 0.052 & 0.297 & 0.923 & 0.610 & 22 \\
\hline 25 & 0.135 & 0.068 & 0.381 & 0.899 & 0.640 & 19 \\
\hline 26 & 0.139 & 0.030 & 0.394 & 0.955 & 0.675 & 18 \\
\hline 27 & 0.136 & 0.092 & 0.384 & 0.862 & 0.623 & 21 \\
\hline 28 & 0.157 & 0.041 & 0.446 & 0.939 & 0.692 & 16 \\
\hline 29 & 0.261 & 0.111 & 0.738 & 0.834 & 0.786 & 11 \\
\hline 30 & 0.237 & 0.043 & 0.673 & 0.936 & 0.804 & 8 \\
\hline 31 & 0.192 & 0.123 & 0.544 & 0.817 & 0.681 & 17 \\
\hline 32 & 0.184 & 0.086 & 0.523 & 0.872 & 0.697 & 15 \\
\hline 33 & 0.276 & 0.145 & 0.783 & 0.784 & 0.783 & 12 \\
\hline 34 & 0.266 & 0.082 & 0.754 & 0.877 & 0.816 & 6 \\
\hline 35 & 0.241 & 0.141 & 0.684 & 0.790 & 0.737 & 14 \\
\hline 36 & 0.263 & 0.032 & 0.747 & 0.952 & 0.849 & 5 \\
\hline 37 & 0.290 & 0.206 & 0.823 & 0.693 & 0.758 & 13 \\
\hline 38 & 0.301 & 0.101 & 0.854 & 0.850 & 0.852 & 4 \\
\hline 39 & 0.302 & 0.177 & 0.855 & 0.736 & 0.795 & 9 \\
\hline 40 & 0.315 & 0.062 & 0.894 & 0.907 & 0.901 & 3 \\
\hline 41 & 0.339 & 0.256 & 0.961 & 0.618 & 0.789 & 10 \\
\hline 42 & 0.353 & 0.126 & 1.000 & 0.812 & 0.906 & 2 \\
\hline 43 & 0.346 & 0.250 & 0.981 & 0.627 & 0.804 & 7 \\
\hline 44 & 0.352 & 0.100 & 0.999 & 0.851 & 0.925 & 1 \\
\hline
\end{tabular}


Table 6. Ranking results of the integrated approach and other methods

\begin{tabular}{|c|c|c|c|c|c|c|}
\hline $\begin{array}{l}\text { Exp. } \\
\text { No. }\end{array}$ & $\begin{array}{c}\text { Proposed } \\
\text { method }\end{array}$ & MOORA & WSPAS & TOPSIS & WASPAS & VIKOR \\
\hline 1 & 44 & 44 & 44 & 44 & 44 & 44 \\
\hline 2 & 43 & 42 & 42 & 42 & 43 & 42 \\
\hline 3 & 41 & 41 & 41 & 41 & 41 & 41 \\
\hline 4 & 42 & 43 & 43 & 43 & 42 & 43 \\
\hline 5 & 38 & 40 & 38 & 40 & 38 & 39 \\
\hline 6 & 37 & 38 & 39 & 39 & 40 & 38 \\
\hline 7 & 39 & 37 & 37 & 37 & 37 & 37 \\
\hline 8 & 40 & 39 & 40 & 38 & 39 & 40 \\
\hline 9 & 26 & 33 & 33 & 34 & 33 & 33 \\
\hline 10 & 36 & 35 & 34 & 33 & 34 & 35 \\
\hline 11 & 35 & 34 & 35 & 35 & 35 & 34 \\
\hline 12 & 34 & 36 & 36 & 36 & 36 & 36 \\
\hline 13 & 27 & 29 & 29 & 30 & 29 & 29 \\
\hline 14 & 32 & 32 & 32 & 32 & 32 & 32 \\
\hline 15 & 31 & 30 & 30 & 29 & 30 & 30 \\
\hline 16 & 30 & 31 & 31 & 31 & 31 & 31 \\
\hline 17 & 24 & 24 & 24 & 26 & 25 & 25 \\
\hline 18 & 33 & 28 & 28 & 28 & 28 & 28 \\
\hline 19 & 25 & 25 & 26 & 25 & 26 & 26 \\
\hline 20 & 29 & 27 & 27 & 27 & 27 & 27 \\
\hline 21 & 20 & 21 & 21 & 21 & 21 & 20 \\
\hline 22 & 28 & 26 & 25 & 24 & 24 & 23 \\
\hline 23 & 23 & 23 & 23 & 23 & 23 & 22 \\
\hline 24 & 22 & 22 & 22 & 22 & 22 & 21 \\
\hline 25 & 19 & 18 & 18 & 17 & 18 & 11 \\
\hline 26 & 18 & 20 & 20 & 20 & 20 & 12 \\
\hline 27 & 21 & 19 & 19 & 19 & 19 & 13 \\
\hline 28 & 16 & 17 & 17 & 18 & 17 & 10 \\
\hline 29 & 11 & 16 & 16 & 15 & 16 & 9 \\
\hline 30 & 8 & 12 & 12 & 11 & 13 & 4 \\
\hline 31 & 17 & 15 & 15 & 12 & 15 & 5 \\
\hline 32 & 15 & 14 & 14 & 8 & 14 & 2 \\
\hline 33 & 12 & 13 & 13 & 14 & 12 & 18 \\
\hline 34 & 6 & 10 & 10 & 6 & 10 & 7 \\
\hline 35 & 14 & 11 & 11 & 10 & 11 & 14 \\
\hline 36 & 5 & 5 & 6 & 3 & 8 & 1 \\
\hline 37 & 13 & 9 & 9 & 9 & 9 & 17 \\
\hline 38 & 4 & 4 & 4 & 4 & 5 & 8 \\
\hline 39 & 9 & 7 & 7 & 7 & 6 & 15 \\
\hline 40 & 3 & 3 & 3 & 1 & 4 & 3 \\
\hline 41 & 10 & 8 & 8 & 13 & 7 & 19 \\
\hline 42 & 2 & 2 & 2 & 5 & 2 & 16 \\
\hline 43 & 7 & 6 & 5 & 16 & 3 & 24 \\
\hline 44 & 1 & 1 & 1 & 2 & 1 & 6 \\
\hline
\end{tabular}

Table 7. The values of Spearman's rank for comparison between optimal operating points ranking

\begin{tabular}{|c|c|c|c|c|c|c|}
\hline Exp. No. & $\begin{array}{c}\text { Proposed } \\
\text { method }\end{array}$ & MOORA & WSPAS & TOPSIS & WASPAS & VIKOR \\
\hline Proposed method & 1 & 0.985 & 0.984 & 0.97 & 0.981 & 0.903 \\
\hline MOORA & - & 1 & 0.999 & 0.984 & 0.997 & 0.899 \\
\hline WSPAS & - & - & 1 & 0.982 & 0.999 & 0.896 \\
\hline TOPSIS & - & - & - & 1 & 0.976 & 0.943 \\
\hline WASPAS & - & - & - & - & 1 & 0.884 \\
\hline VIKOR & - & - & - & - & - & 1 \\
\hline
\end{tabular}

